\title{
Adaptabilidade e estabilidade de genótipos de trigo irrigado no Cerrado do Brasil Central
}

\begin{abstract}
Julio Cesar Albrecht $t^{(1)}$, Eduardo Alano Vieira ${ }^{(1)}$, Marcio Só e Silva(2), José Maria Vilela de Andrade(1), Pedro Luiz Scheeren(2), Maria da Glória Trindade ${ }^{(2)}$, Joaquim Soares Sobrinho(2), Cantidio Nicolau Alves de Sousa(2), Wagner Pereira Reis ${ }^{(3)}$, Walter Quadros Ribeiro Júnior ${ }^{(2)}$, Vanoli Fronza ${ }^{(4)}$, Adeliano Cargnin ${ }^{(1)}$ e Celso Hideo Yamanaka ${ }^{(5)}$

(1)Embrapa Cerrados, BR 020, Km 18, CEP 73310-970 Planaltina, DF. E-mail: julio@cpac.embrapa.br, vieiraea@cpac.embrapa.br, vilela@cpac.embrapa.br, adeliano.cargnin@cpac.embrapa.br (2)Embrapa Trigo, BR 285, Km 174, CEP 99001-970 Passo Fundo, RS. E-mail: soesilva@cnpt.embrapa.br, scheeren@cnpt.embrapa.br, mgloria@cnpaf.embrapa.br, jss@nanet.com.br, cantidiosousa@yahoo com.br, walter@cpac.embrapa.br (3)Universidade Federal de Lavras, CEP 37200-000 Lavras, MG. E-mail: wagner@ufla.br ${ }^{(4)}$ Embrapa Soja, Rod. Carlos João Strass, Distrito de Warta, CEP 86001-970 Londrina, PR. E-mail: vanoli@cnps.embrapa.br (5)Coopadap, MG 235, Km 01, CEP 38800-000 São Gotardo, MG. E-mail: celso@coopadap.com.br
\end{abstract}

Resumo - O objetivo deste trabalho foi estimar a adaptabilidade e estabilidade de genótipos de trigo irrigado, nas condições do Cerrado do Brasil Central. O rendimento de grãos de cinco cultivares e nove linhagens de trigo irrigado foram aferidos no ensaio de valor de cultivo e uso. Os ensaios foram conduzidos nos anos de 2005 e 2006, em seis locais em Minas Gerais, três em Goiás e um no Distrito Federal. Os dados de rendimento de grãos foram submetidos à análise de variância individual e à análise de variância conjunta, para a estimativa dos parâmetros de adaptabilidade e estabilidade. Verificaram-se diferenças significativas, entre os genótipos, em 14 dos 16 ambientes avaliados. Nenhum dos genótipos avaliados apresentou o comportamento ideal preconizado pelo método de Cruz e colaboradores. Destacaram-se a cultivar BRS 264 e a linhagem CPAC 02167, pela superioridade em todas as condições do Cerrado do Brasil Central (adaptabilidade geral). Entre os demais genótipos avaliados, destacaram-se as cultivares BRS 207 e EMBRAPA 22, responsivas à melhoria das condições ambientais, e as cultivares BRS 254 e EMBRAPA 42, pela adaptabilidade específica a ambientes desfavoráveis ao cultivo de trigo irrigado.

Termos para indexação: Triticum aestivum, interação genótipo x ambiente, melhoramento genético, recomendação de cultivares.

\section{Adaptability and stability of irrigated wheat genotypes in the Cerrado of Central Brazil}

\begin{abstract}
The aim of this work was to estimate the adaptability and stability of irrigated wheat genotypes under conditions of Central Brazil savannah area. Grain yield of five cultivars and nine lines of irrigated wheat was measured in assays of cultivation value and use. The assays were conducted during the years 2005 and 2006, in six locations in Minas Gerais State, three in Goiás State and one in Federal District. The data of grain yield were submitted to individual and joint ANOVA, in order to estimate the adaptability and stability parameters. Significant differences were detected between genotypes in 14 of the 16 locations evaluated. None of the evaluated genotypes have presented the behavior predicted by the method of Cruz and collaborators. Cultivar BRS 264 and the CPAC 02167 lineage were superior in all the tested conditions in the Central Brazil savannah (general adaptability). Among the other evaluated genotypes, it can be highlighted the responsiveness of the cultivars BRS 207 and EMBRAPA 22 to the improvement of environmental conditions, and the specific fitness of BRS 254 and EMBRAPA 42 cultivars to environments unfavorable to irrigated wheat.
\end{abstract}

Index terms: Triticum aestivum, genotype x environment interaction, genetic improvement, varieties recommendation.

\section{Introdução}

A região do Cerrado do Brasil Central tem grande potencial para a expansão da cultura de trigo, por oferecer ótimas condições de clima e solo, posição estratégica de mercado e capacidade de industrialização, além de poder ser colhido na entressafra da produção dos estados do Sul e da Argentina e, com características superiores de qualidade industrial para panificação (alta força de glúten e estabilidade) (Albrecht et al., 2006a).

A seleção de cultivares com: alto potencial produtivo, elevada estabilidade de produção e alta capacidade de adaptação às condições para as quais será indicada, aliada às qualidades agronômicas superiores (estatura, 
ciclo, resistência a pragas e doenças, qualidades nutricionais e industriais, entre outras), é o principal objetivo da maioria dos programas de melhoramento genético vegetal (Allard, 1999). Para que o genótipo ideal possa ser identificado, é necessária a realização de experimentos em diferentes locais contrastantes, em que vários genótipos são avaliados (Cargnin et al., 2006a). Entretanto, para determinados caracteres de interesse, principalmente rendimento de grãos, ocorre a interação dos genótipos com os ambientes (GxE), que é uma resposta diferencial dos genótipos frente à modificação do ambiente (Allard, 1999). Essa resposta diferencial dificulta a identificação dos genótipos superiores, quando ocorre inconstância no desempenho destes nos diferentes ambientes (Carvalho et al., 2002).

A simples estimativa do componente da interação genótipo com ambiente, apesar de importante, não fornece informações sobre o comportamento dos genótipos em relação às variações de ambiente (Cruz \& Regazzi, 1997). Assim, diversos métodos têm sido propostos para estimar parâmetros de adaptabilidade e estabilidade, para caracterizar o desempenho relativo dos genótipos, quando submetidos a diferentes condições de ambiente (Eberhart \& Russell, 1966; Tai, 1971; Lin \& Binns, 1988; Cruz et al., 1989), o que permite a identificação de genótipos com comportamento estável e que respondam às variações de ambiente. Desde que foram desenvolvidos, os métodos baseados em análises de regressão têm sido os mais utilizados, quer seja pela utilização de apenas um segmento de reta (Eberhart \& Russell, 1966) ou de dois segmentos de reta, os quais se destacam por gerar informações a respeito do desempenho dos genótipos em ambientes favoráveis e desfavoráveis (Cruz et al., 1989). Entretanto, nem todos os dados se ajustam a modelos lineares, o que abre a possibilidade da utilização de metodologias não paramétricas na estimativa da adaptabilidade e estabilidade (Cruz \& Carneiro, 2003).

Entre os métodos não paramétricos, se destaca a proposta por Lin \& Binns (1988), pela qual os genótipos são classificados de acordo com um parâmetro de adaptabilidade e estabilidade geral. Essa metodologia foi aprimorada por Carneiro (1998), por meio da decomposição desse parâmetro considerando-se ambientes favoráveis e desfavoráveis.

Nas últimas décadas, estudos de adaptabilidade e estabilidade do rendimento de grãos vêm sendo empregados com êxito no melhoramento genético de diversas espécies, entre elas: trigo (Felício et al., 2001a, 2001b; Caierão et al., 2006); amendoim (Oliveira et al., 2006a); soja (Silva et al., 2006); feijão (Oliveira et al., 2006b); algodão (Souza et al., 2006); milho (Carvalho et al., 2005), e têm auxiliado na recomendação de cultivares e na identificação de genótipos com alta capacidade produtiva, boa adaptabilidade e estabilidade. Apesar de haver alguns trabalhos (Felício et al., 2001a, 2001b; Amorim et al., 2006) sobre adaptabilidade e estabilidade com genótipos de trigo irrigado, sob condições de Cerrado no Brasil Central, ainda não foram desenvolvidos em quantidade suficiente.

O objetivo deste trabalho foi estimar a adaptabilidade e a estabilidade de genótipos de trigo irrigado, nas condições do Cerrado do Brasil Central.

\section{Material e Métodos}

Dados experimentais do caráter rendimento de grãos foram avaliados nos ensaios de valor de cultivo e uso (VCU) de trigo irrigado, em relação às condições do Cerrado do Brasil Central, coordenados pela Comissão Centro-Brasileira de Pesquisa de Trigo. Os ensaios foram conduzidos nos anos de 2005 e 2006, em seis locais em Minas Gerais, três locais em Goiás e um no Distrito Federal (Tabela 1).

Por razões bióticas e abióticas, houve perda de experimentos em quatro locais, e restaram, portanto, dados de 16 ambientes para as análises (Tabela 1). Nos ensaios, foram avaliados 14 genótipos de trigo irrigado, tendo sido cinco cultivares (EMBRAPA 42, EMBRAPA 22, BRS 207, BRS 254 e BRS 264), que se destacam por apresentar alta produtividade e especificações de qualidade industrial, desejadas pela indústria moageira (Albrecht et al., 2004, 2005, 2006a, 2006b), e nove linhagens promissoras do programa de melhoramento da Embrapa (CPAC 021031, CPAC 02154, CPAC 0236, CPAC 02144, CPAC 02167 e CPAC 02181, PF 013405, PF 013431 e PF 013453).

Os experimentos foram conduzidos em delineamento de blocos ao acaso, com quatro repetições. Cada parcela foi constituída de cinco linhas de $5 \mathrm{~m}$ de comprimento, espaçadas de 0,20 m, e a área útil da parcela foi formada pelas três fileiras internas de $4 \mathrm{~m}$ de comprimento. Todos os tratos culturais, inclusive a irrigação, foram executados de acordo com as recomendações técnicas para a cultura do trigo (Comissão Centro-Brasileira de Pesquisa de Trigo, 2005). O rendimento de grãos, obtido por meio da pesagem das parcelas, foi corrigido para $13 \%$ de umidade e foi, posteriormente, transformado para $\mathrm{kg} \mathrm{ha}^{-1}$. 
Os dados foram submetidos à análise de variância individual e, posteriormente, foi efetuada a análise de variância conjunta, em que o efeito dos genótipos foi considerado fixo e os demais aleatórios (Cruz \& Regazzi, 1997). Para a estimativa dos parâmetros de adaptabilidade e estabilidade, foram utilizados os métodos de Cruz et al. (1989) e Lin \& Binns (1988) modificado por Carneiro (1998).

O método de Cruz et al. (1989) tem por base a análise de regressão bissegmentada e como parâmetros de adaptabilidade a média $\left(\beta_{0 \mathrm{i}}\right)$, a resposta linear aos ambientes desfavorábeis $\left(\beta_{1 \mathrm{i}}\right)$ e a resposta linear aos ambientes favoráveis $\left(\beta_{1 \mathrm{i}}+\beta_{2 \mathrm{i}}\right)$. Os parâmetros de estabilidade são os desvios da regressão $\left(\sigma^{2}{ }_{\delta i}\right)$, em que $\mathrm{R}^{2}$ é uma medida auxiliar da previsibilidade de determinado genótipo. O modelo adotado foi: $Y_{\mathrm{ij}}=\beta_{0 \mathrm{i}}+$ $\beta_{1 \mathrm{i}} \mathrm{I}_{\mathrm{j}}+\beta_{2 \mathrm{i}} \mathrm{T}(\mathrm{Ij})+\sigma_{\mathrm{ij}}+\mathrm{e}_{\mathrm{ij}}$, em que: $\mathrm{Y}_{\mathrm{ij}}$ é a média da $\mathrm{i}-$ ésima cultivar no j-ésimo ambiente; $\beta_{0 \mathrm{i}}$ é a média geral da cultivar $\mathrm{i}$; $\mathrm{I}_{\mathrm{j}}$ é o índice ambiental; $\mathrm{T}\left(\mathrm{I}_{\mathrm{j}}\right)=0$ se $\mathrm{I}_{\mathrm{j}}<0$; $\mathrm{T}\left(\mathrm{I}_{\mathrm{j}}\right)=\mathrm{I}_{\mathrm{j}}-\mathrm{I}_{+}$se $\mathrm{I}_{\mathrm{j}}>0$, em que $\mathrm{I}_{+}$é a média dos índices $\mathrm{I}_{\mathrm{j}}$ positivos; $\beta_{1 \mathrm{i}}$ é o coeficiente de regressão linear associado à variável $\mathrm{I}_{\mathrm{j}} ; \beta_{2 \mathrm{i}}$ é o coficiente de regressão linear associado à variável $\mathrm{T}\left(\mathrm{I}_{\mathrm{j}}\right) ; \sigma_{\delta \mathrm{i}}$ é o desvio da regressão linear; e e $\mathrm{e}_{\mathrm{ij}}$ é o erro experimental médio.

O método de Lin \& Binns (1988) tem como medida, para estimar o desempenho de cada genótipo $\left(\mathrm{P}_{\mathrm{ig}}\right)$, o quadrado médio da distância entre a média do genótipo e a resposta média máxima para todos os ambientes.
Desde que a resposta média máxima esteja no limite superior, em cada ambiente, um quadrado médio $\left(\mathrm{P}_{\mathrm{i}}\right)$ menor indicará a superioridade geral do genótipo. Essa medida é dada por:

$\mathrm{P}_{\mathrm{i}}=\frac{\sum_{\mathrm{j}=1}^{\mathrm{n}}\left(\mathrm{Y}_{\mathrm{ij}}-\mathrm{M}_{\cdot \mathrm{j}}\right)^{2}}{2 \mathrm{a}}$,

em que: $\mathrm{P}_{\text {ig }}$ é a medida de adaptação e estabilidade de comportamento do genótipo $\mathrm{i} ; \mathrm{Y}_{\mathrm{ij}}$ é a produtividade do i-ésimo genótipo no j-esimo ambiente; $\mathrm{M}_{\cdot \mathrm{j}}$ é a resposta máxima entre todos os genótipos no ambiente; a é o número de ambientes.

A modificação do método de Lin \& Binns (1988), proposta por Carneiro (1998), preconiza a decomposição da medida $\mathrm{P}_{\mathrm{ig}}$, nas suas partes relativas a ambientes favoráveis $\left(\mathrm{P}_{\mathrm{if}}\right)$ e a ambientes desfavoráveis $\left(\mathrm{P}_{\mathrm{id}}\right)$. A classificação dos ambientes em favoráveis ou desfavoráveis é efetuada por meio do índice de ambiente, que é a diferença entre a média dos genótipos avaliados em dado ambiente e a média geral dos experimentos.

Para ambiente favorável (índice de ambiente $\geq 0$ ), estima-se:

$$
P_{i}=\frac{\sum_{j=1}^{f}\left(Y_{i j}-M_{\cdot j}\right)^{2}}{2 f},
$$

Tabela 1. Ano de condução do experimento, altitude, latitude, longitude, rendimento médio de grãos $(\mathrm{RMG})(\mathrm{kg}$ ha-1 $)$, índice ambiental (IA) $\left(\mathrm{kg} \mathrm{ha}^{-1}\right)$, quadrado médio da fonte de variação genótipos ( $\left.\mathrm{QM}_{\text {genótipos }}\right)$, quadrado médio da fonte de variação resíduo $\left(\mathrm{QM}_{\text {resíduo }}\right)$ e coeficiente de variação $(\mathrm{CV})$, referentes a ensaios de valor de cultivo e uso (VCU) de trigo irrigado, conduzidos no Cerrado do Brasil Central, nos anos de 2005 e 2006.

\begin{tabular}{|c|c|c|c|c|c|c|c|c|c|}
\hline Ambiente & Ano & Altitude $(\mathrm{m})$ & Latitude & Longitude & RMG & IA & $\mathrm{QM}_{\text {genótipos }}$ & $\mathrm{QM}_{\text {residuo }}$ & $\mathrm{CV}(\%)$ \\
\hline Planaltina, DF & 2005 & 1.007 & $15^{\circ} 35^{\prime} 00^{\prime \prime}$ & $47^{\circ} 42^{\prime} 00^{\prime \prime}$ & 5.919 & 1.817 & $2.273 .452 *$ & 363.716 & 10 \\
\hline Planaltina, DF & 2006 & 1.007 & $15^{\circ} 35^{\prime} 00^{\prime \prime}$ & $47^{\circ} 42^{\prime} 00^{\prime \prime}$ & 6.074 & 1.972 & $2.955 .982 *$ & 239.219 & 8 \\
\hline Unaí, MG & 2005 & 1.052 & $16^{\circ} 22^{\prime} 45^{\prime \prime}$ & $46^{\circ} 53^{\prime} 45^{\prime \prime}$ & 6.530 & 2.428 & $3.254 .569^{*}$ & 166.879 & 6 \\
\hline Coromandel, $\mathrm{MG}$ & 2006 & 1.100 & $18^{\circ} 33^{\prime} 34^{\prime \prime}$ & $47^{\circ} 01^{\prime} 01^{\prime \prime}$ & 4.048 & -54 & $2.134 .900 *$ & 77.739 & 7 \\
\hline Ituiutaba, GO & 2006 & 600 & $18^{\circ} 59^{\prime} 09^{\prime \prime}$ & $49^{\circ} 27^{\prime} 53^{\prime \prime}$ & 3.295 & -807 & $3.443 .604 *$ & 190.424 & 13 \\
\hline Indianópolis, MG & 2005 & 800 & $19^{\circ} 02^{\prime} 19^{\prime \prime}$ & $47^{\circ} 55^{\prime} 01^{\prime \prime}$ & 5.493 & 1.391 & $2.897 .786^{*}$ & 255.350 & 9 \\
\hline Santo Antônio de Goiás, GO & 2005 & 720 & $16^{\circ} 40^{\prime} 00^{\prime \prime}$ & $49^{\circ} 15^{\prime} 00^{\prime \prime}$ & 3.570 & -532 & $1.366 .584 *$ & 377.262 & 17 \\
\hline Santo Antônio de Goiás, GO & 2006 & 720 & $16^{\circ} 40^{\prime} 00^{\prime \prime}$ & $49^{\circ} 15^{\prime} 00^{\prime \prime}$ & 2.672 & -1.430 & $331.055^{\mathrm{ns}}$ & 175.233 & 16 \\
\hline Urutaí, GO & 2005 & 800 & $17^{\circ} 15^{\prime} 11^{\prime \prime}$ & $48^{\circ} 12^{\prime} 60^{\prime \prime}$ & 3.343 & -759 & $546.072 *$ & 265.411 & 15 \\
\hline Urutaí, GO & 2006 & 800 & $17^{\circ} 15^{\prime} 11^{\prime \prime}$ & $48^{\circ} 12^{\prime} 60^{\prime \prime}$ & 2.567 & -1.535 & $487.745^{*}$ & 173.750 & 16 \\
\hline Lavras, MG & 2005 & 919 & $21^{\circ} 14^{\prime} 00^{\prime \prime}$ & $15^{\circ} 00^{\prime} 00^{\prime \prime}$ & 3.199 & -903 & $2.346 .471 *$ & 148.117 & 12 \\
\hline Lavras, MG & 2006 & 919 & $21^{\circ} 14^{\prime} 00^{\prime \prime}$ & $15^{\circ} 00^{\prime} 00^{\prime \prime}$ & 2.565 & -1.537 & $2.666 .815^{*}$ & 191.920 & 17 \\
\hline Uberaba, MG & 2005 & 743 & $19^{\circ} 45^{\prime} 00^{\prime \prime}$ & $47^{\circ} 55^{\prime} 00^{\prime \prime}$ & 3.874 & -228 & $2.269 .847^{*}$ & 156.982 & 10 \\
\hline Uberaba, MG & 2006 & 743 & $19^{\circ} 45^{\prime} 00^{\prime \prime}$ & $47^{\circ} 55^{\prime} 00^{\prime \prime}$ & 3.799 & -303 & $1.394 .707 *$ & 177.770 & 11 \\
\hline Rio Paranaíba, MG & 2005 & 1.026 & $19^{\circ} 11^{\prime} 37^{\prime \prime}$ & $46^{\circ} 14^{\prime} 50^{\prime \prime}$ & 4.077 & -25 & $1.198 .988^{*}$ & 129.183 & 9 \\
\hline Rio Paranaíba, MG & 2006 & 1.026 & $19^{\circ} 11^{\prime} 37^{\prime \prime}$ & $46^{\circ} 14^{\prime} 50^{\prime \prime}$ & 4.611 & 509 & $1.960 .791 *$ & 264.796 & 11 \\
\hline Média & & & & & 4.102 & & & & \\
\hline Maior $\mathrm{QM}_{\text {residuo }} /$ menor $\mathrm{QM}_{\text {residuo }}$ & & & & & & & & 4,85 & \\
\hline
\end{tabular}

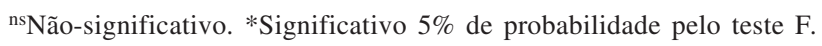


em que: $\mathrm{P}_{\text {if }}$ é a medida de adaptação e estabilidade de comportamento do genótipo em ambientes favoráveis i; $\mathrm{Y}_{\mathrm{ij}}$ é a produtividade do i-ésimo genótipo, no j-ésimo ambiente; $M_{. j}$ é a resposta máxima entre todos os genótipos no ambiente; fé o número de ambientes favoráveis.

Para ambiente desfavorável (índice de ambiente $<0$ ), estima-se:

$$
\mathrm{P}_{\mathrm{i}}=\frac{\sum_{\mathrm{j}=1}^{\mathrm{d}}\left(\mathrm{Y}_{\mathrm{ij}}-\mathrm{M}_{\cdot \mathrm{j}}\right)^{2}}{2 \mathrm{~d}},
$$

em que: $\mathrm{P}_{\mathrm{id}}$ é a medida de adaptação e estabilidade de comportamento do genótipo, em ambiente desfavorável $\mathrm{i} ; \mathrm{Y}_{\mathrm{ij}}$ é a produtividade do i-ésimo genótipo, no j-ésimo ambiente; $M_{. j}$ é a resposta máxima entre todos os genótipos no ambiente; d é o número de ambientes desfavoráveis. Todas as análises foram realizadas com o auxílio do programa Genes, aplicativo computacional em genética e estatística, desenvolvido na Universidade Federal de Viçosa (Cruz, 2006).

\section{Resultados e Discussão}

Os resultados das análises de variância individuais revelaram a existência de diferenças significativas a 5\% de probabilidade pelo teste $\mathrm{F}$, entre os genótipos, quanto ao rendimento de grãos em todos os ambientes, exceção feita a Santo Antônio de Goiás/2006 (GO), onde os genótipos não se diferenciaram (Tabela 1). Portanto, evidencia-se a existência de variabilidade de potencial produtivo entre os genótipos avaliados, nas diferentes condições ambientais do Cerrado.

Entre os 16 ambientes avaliados, cinco foram classificados como favoráveis (índices de ambiente positivos) e 11 como desfavoráveis (índices de ambiente negativos). As médias de produtividade nos ambientes, que variaram de 6.530 a $2.565 \mathrm{~kg} \mathrm{ha}^{-1}$, são evidências das diferenças pronunciadas no potencial de produtividade de trigo, nos ambientes avaliados.

Entre os ambientes classificados como desfavoráveis (Tabela 1), em Coromandel/2006 (MG) e Rio Paranaíba/ 2005 (MG), os índices de ambiente estiveram muito próximos de zero, o que é evidência de que, por muito pouco, esses ambientes não foram classificados entre os favoráveis, o que era esperado pela altitude desses locais (acima de $1.000 \mathrm{~m}$ ). O aumento da altitude proporciona redução da temperatura que, assim, afeta vários caracteres da planta de trigo e como consequiência, eleva a produtividade. $\mathrm{O}$ estresse térmico constitui fator limitante em regiões do Brasil Central situadas em altitudes inferiores a $800 \mathrm{~m}$, em razão de ocasionar redução significativa da produtividade (Albrecht, 2006b). As chuvas que ocorreram na época da colheita em 2006 e as temperaturas médias mais altas, durante o ciclo da cultura, em 2005, foram as causas dos baixos índices de ambiente desses dois locais. De fato, muitos genótipos apresentam alta suscetibilidade à germinação na espiga e chegam a desencadear o processo de germinação pelo efeito da alta temperatura e umidade, como é o caso da cultivar BRS 207, com alta atividade da enzima alfa-amilase, o que ocasiona perda da massa dos grãos pela respiração e, conseqüentemente, menor rendimento de grãos (Cargnin et al., 2006b)

Os coeficientes de variação das análises de variância individuais apresentaram valores entre 6 e $17 \%$ e foram classificados como médios, de acordo com Lúcio et al. (1999), o que revela boa precisão experimental. Os ambientes foram avaliados conjuntamente (Tabela 1), porque os coeficientes de variação se situaram abaixo do limite máximo aceitável de 20\% (Portaria no 294 Lei de proteção de cultivares), e a razão entre o maior e o menor valor do quadrado médio do resíduo foi inferior a 7, que, segundo Cruz \& Regazzi (1997), é o limite que possibilita a análise de forma conjunta dos experimentos.

A análise de variância conjunta possibilita a verificação do efeito significativo de genótipos, ambientes e também da interação genótipos $\mathrm{x}$ ambientes, quanto ao caráter rendimento de grãos, o que é evidência de que as classificações dos genótipos não foram coincidentes nos ambientes de avaliação (Tabela 2). Interações significativas entre genótipos e ambientes, quanto ao caráter rendimento de grão, vêm sendo

Tabela 2. Resumo da análise de variância conjunta do caráter rendimento médio de grãos, em 14 genótipos de trigo, em 16 ambientes do Cerrado do Brasil Central ${ }^{(1)}$.

\begin{tabular}{lrc}
\hline Fonte de variação & GL & Quadrado médio \\
\hline Blocos/ambientes & 48 & 487.231 \\
Ambientes (A) & 15 & $91.521 .265^{*}$ \\
Genótipos (G) & 13 & $14.660 .099^{*}$ \\
Gx A & 195 & $1.124 .618^{*}$ \\
Resíduo & 624 & 209.609 \\
\hline
\end{tabular}

${ }^{(1)} \mathrm{O}$ coeficiente de variação foi $11 \%$. * Significativo a $5 \%$ de probabilidade pelo teste $\mathrm{F}$. 
relatadas com frequiência em trabalhos com a cultura do trigo no Brasil (Felício et al., 2001a, 2001b; Cargnin et al., 2006a).

Trabalhos de mapeamento genético de QTL (locos de um caráter de herança quantitativa) apontam que a causa genética da interação genótipos e ambientes pode ser explicada pela interação entre QTL e ambientes. Assim, a base genética da interação genótipos e ambientes origina-se da expressão diferencial dos QTL ao longo dos ambientes e pode ocorrer de três maneiras: um QTL se expressa em um ambiente e não em outro; um QTL se expressa fortemente em determinado ambiente e fracamente em outro; um QTL se expressa de forma diferenciada em diferentes ambientes. Todos os três casos de interação entre QTL e ambientes já foram detectados em trigo (Kumar et al., 2007; Snape et al., 2007). Portanto, a alta interação entre genótipos e ambientes, detectada para o caráter rendimento de grãos no presente trabalho, é indicativo de que há, em sua base genética, a ocorrência dos fenômenos genéticos de penetrância e expressividade em seus locos de herança quantitativa.

Em relação aos parâmetros de adaptabilidade e estabilidade, estimados conforme Cruz et al. (1989), nenhum dos genótipos avaliados apresentou o comportamento ideal preconizado pelo método: média alta (alto $\beta_{0}$ ), adaptabilidade a ambientes desfavoráveis $\left(\beta_{1}<1\right)$, responsividade a melhoria ambiental $\left(\beta_{1}+\beta_{2}>1\right)$, desvios da regressão $\left(\sigma^{2}{ }_{\text {ii }}\right)$ não significativos (alta estabilidade) e $\mathrm{R}^{2}>0,80$ que, segundo Cruz \& Regazzi
(1997), são indicativos de que o genótipo apresenta previsibilidade razoável por apresentar um bom ajuste às retas da regressão (Tabela 3). Portanto, a seleção e recomendação dos genótipos deverão ser específicas e individuais para cada situação de ambiente favorável e desfavorável.

Assim, foram considerados como genótipos com potencial de recomendação os que evidenciaram: produtividade média de grãos superior à média geral dos ambientes $\left(\beta_{0}\right)$, nos ambientes desfavoráveis (MD) e nos ambientes favoráveis (MF), bem como baixa sensibilidade a ambientes desfavoráveis $\left(\beta_{1} \leq 1\right)$, responsividade à melhoria ambiental $\left(\beta_{1}+\beta_{2} \geq 1\right)$, além do máximo de previsibilidade (estabilidade) com desvios da regressão $\left(\sigma_{\delta \mathrm{i}}^{2}\right)$ não significativos e/ou $\mathrm{R}^{2}>0,80$. Portanto, os genótipos que mais se aproximaram desses critérios foram as cultivares EMBRAPA 22, BRS 207 e BRS 254, bem como as linhagens CPAC 0236 e CPAC 02167. A cultivar BRS 264 também merece destaque, pois expressou sensibilidade a ambientes desfavoráveis $\left(\beta_{1}>1\right)$, porém foi a mais produtiva, e, embora não tenha respondido à melhoria de ambiente $\left(\beta_{1}+\beta_{2}=1\right)$, foi a que apresentou o maior rendimento de grãos (Tabela 3). Isso evidencia que a BRS 264 possui alto potencial produtivo em qualquer ambiente, porém demonstrou ter atingido o seu máximo produtivo com a tecnologia utilizada atualmente, ao não responder à melhoria de ambiente. A resposta à melhoria de ambiente dessa cultivar acontece somente em ambientes desfavoráveis.

Tabela 3. Média geral $\left(\beta_{0}\right)$, média em ambientes desfavoráveis (MD), média em ambientes favoráveis (MF), parâmetro de adaptabilidade $\left(\beta_{1}\right)$, responsividade $\left(\beta_{1}+\beta_{2}\right)$, desvio de regressão $\left(\sigma^{2}{ }_{\delta}\right)$ e coeficiente de determinação $\left(\mathrm{R}^{2}\right)$ do caráter rendimento médio de grãos ( $\mathrm{kg} \mathrm{ha}^{-1}$ ), estimados por meio do método de Cruz et al. (1989), em 14 genótipos de trigo irrigado, avaliados em 16 ambientes do Cerrado do Brasil Central.

\begin{tabular}{|c|c|c|c|c|c|c|c|}
\hline Genótipo & $\beta_{0}$ & MD & MF & $\beta_{1}$ & $\beta_{1}+\beta_{2}$ & $\sigma_{\delta \mathrm{i}}^{2}$ & $\mathrm{R}^{2}$ \\
\hline EMBRAPA 42 & 4.086 & 3.478 & 5.425 & $0,89 *$ & $1,16^{\mathrm{ns}}$ & $890.670 *$ & 0,88 \\
\hline EMBRAPA 22 & 4.293 & 3.427 & 6.199 & $1,08^{\mathrm{ns}}$ & $0,95^{\mathrm{ns}}$ & $775.210^{*}$ & 0,92 \\
\hline BRS 207 & 4.453 & 3.638 & 6.249 & $1,08^{\mathrm{ns}}$ & $0,97^{\mathrm{ns}}$ & $1.163 .304 *$ & 0,88 \\
\hline BRS 254 & 4.426 & 3.656 & 6.121 & $1,02^{\mathrm{ns}}$ & $1,46^{*}$ & $1.210 .746^{*}$ & 0,88 \\
\hline BRS 264 & 4.740 & 3.835 & 6.733 & $1,25^{*}$ & $0,91^{\mathrm{ns}}$ & $1.901 .192 *$ & 0,86 \\
\hline CPAC 021031 & 4.271 & 3.472 & 6.029 & $1,17^{*}$ & $0,75^{\mathrm{ns}}$ & $726.389 *$ & 0,93 \\
\hline CPAC 02154 & 4.094 & 3.325 & 5.786 & $1,06^{\mathrm{ns}}$ & $0,66^{*}$ & $289.492^{\text {ns }}$ & 0,97 \\
\hline СРAC 0236 & 4.271 & 3.503 & 5.963 & $1,07^{\mathrm{ns}}$ & $1,36^{*}$ & $664.258 *$ & 0,93 \\
\hline CPAC 02144 & 4.241 & 3.450 & 5.983 & $0,98^{\text {ns }}$ & $0,86^{\mathrm{ns}}$ & $1.887 .628 *$ & 0,79 \\
\hline CPAC 02167 & 4.447 & 3.699 & 6.094 & $1,04^{\mathrm{ns}}$ & $1,23^{\mathrm{ns}}$ & $622.212 *$ & 0,93 \\
\hline CPAC 02181 & 4.045 & 3.246 & 5.803 & $1,09^{\mathrm{ns}}$ & $1,38^{*}$ & $512.698 *$ & 0,95 \\
\hline PF 013405 & 3.146 & 2.570 & 4.412 & $0,71^{*}$ & $0,68^{*}$ & $1.492 .273 *$ & 0,71 \\
\hline PF 013431 & 3.034 & 2.566 & 4.065 & $0,62 *$ & $0,70^{\mathrm{ns}}$ & $594.210^{*}$ & 0,83 \\
\hline PF 013453 & 3.879 & 3.237 & 5.290 & $0,94^{\mathrm{ns}}$ & $0,93^{\text {ns }}$ & $966.832 *$ & 0,87 \\
\hline Média & 4.102 & 3.364 & 5.725 & & & & \\
\hline
\end{tabular}

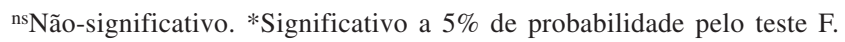


O método de Lin \& Binns (1988), modificado por Carneiro (1998), revelou que os genótipos mais estáveis são os que apresentaram menores valores $\mathrm{P}_{\mathrm{ig}}$, isto é, os genótipos que tiveram os menores desvios em torno da produtividade máxima de cada ambiente; os mais responsivos à melhoria dos ambientes foram aqueles com menores valores de $\mathrm{P}_{\mathrm{if}}$; e os mais adaptados a ambientes desfavoráveis foram aqueles com menores valores de $\mathrm{P}_{\text {id. }}$ Portanto, merecem destaque a cultivar BRS $264 \mathrm{e}$ a linhagem CPAC 02167 (Tabela 4), as quais tiveram os melhores desempenhos, quando foram considerados todos os ambientes e quando foram considerados apenas os ambientes favoráveis ou desfavoráveis (adaptabilidade geral). Para condições específicas de ambiente, destacaram-se, ainda, as cultivares BRS 254 e EMBRAPA 42 para ambientes desfavoráveis, e as cultivares BRS 207 e EMBRAPA 22, para ambientes favoráveis (Tabela 4).

As linhagens PF 013405, PF 013431 e PF 013453 merecem destaque negativo, em razão de terem apresentado médias baixas de produtividade de grãos, em todas as condições avaliadas, e de terem sempre se situado entre os piores genótipos, em ambos os métodos avaliados. Essas linhagens apresentaram estatura de plantas inferior a $70 \mathrm{~cm}$, consideradas linhagens anãs.

De modo geral, para todas as condições de ambiente (adaptabilidade geral), destacaram-se a cultivar BRS 264 e a linhagem CPAC 02167, a qual mostra-se com grande potencial para ser lançada como nova cultivar de trigo irrigado, para as condições do Cerrado do Brasil Central. Também podem ser recomendadas, para condições favoráveis, as cultivares BRS 207 e EMBRAPA 22, e para condições desfavoráveis, as cultivares BRS 254 e EMBRAPA 42. A linhagem CPAC 0236, apesar de ter recebido destaque positivo conforme Cruz et al. (1989), não foi recomendada, em razão de ter apresentado médias inferiores à da cultivar CPAC 02167 , em todas as condições, e de ter se situado em região intermediária de ranking segundo Lin \& Binns (1988), modificado por Carneiro (1998).

O estudo de adaptabilidade e estabilidade, pelo método de Lin \& Binns (1988), modificado por Carneiro (1998), permite a recomendação imediata dos genótipos, em razão da unicidade do parâmetro e, ainda, uma avaliação do comportamento de cada genótipo e de sua resposta em função da variação de ambiente. Deve-se, ainda, salientar que as diferenças em relação ao ideótipo são elevadas ao quadrado e apresentam, portanto, propriedade de variância que é traduzida por este método em estabilidade de comportamento. Por este método, os ambientes similares têm menor peso, o que faz com que a regressão seja mais representativa do comportamento dos genótipos. Verifica-se, portanto, a grande utilidade e eficiência deste método na recomendação de cultivares. Resultados semelhantes também foram obtidos por Carbonell et al. (2001) e Oliveira et al. (2006b), ambos os trabalhos com a cultura do feijão.

Tabela 4. Parâmetro de estabilidade $\left(\mathrm{P}_{\mathrm{ig}}\right)$ do caráter rendimento médio de grãos $(\mathrm{RMG}) \mathrm{em} \mathrm{kg} \mathrm{ha}{ }^{-1}$, estimado por meio do método de Lin \& Binns (1988), modificado por Carneiro (1998), em 14 genótipos de trigo irrigado, avaliados em 16 ambientes do Cerrado do Brasil Central, a partir de sua decomposição em ambientes favoráveis $\left(\mathrm{P}_{\mathrm{if}}\right)$, desfavoráveis $\left(\mathrm{P}_{\text {id }}\right)$ e sua classificação (Class.).

\begin{tabular}{|c|c|c|c|c|c|c|c|}
\hline Genótipo & RMG & $P_{i g}$ & Class. & $\mathrm{P}_{\text {if }}$ & Class. & $P_{i d}$ & Class. \\
\hline EMBRAPA 42 & 4.086 & 757.969 & 10 & 1.140 .291 & 11 & 584.186 & 4 \\
\hline EMBRAPA 22 & 4.293 & 562.962 & 5 & 344.299 & 4 & 662.355 & 6 \\
\hline BRS 207 & 4.453 & 485.757 & 4 & 209.496 & 2 & 611.330 & 5 \\
\hline BRS 254 & 4.426 & 402.385 & 3 & 376.196 & 5 & 414.290 & 3 \\
\hline BRS 264 & 4.740 & 264.342 & 1 & 17.222 & 1 & 376.669 & 1 \\
\hline CPAC 021031 & 4.271 & 634.139 & 7 & 407.339 & 6 & 737.231 & 8 \\
\hline CPAC 02154 & 4.094 & 745.434 & 9 & 687.945 & 9 & 771.565 & 10 \\
\hline CPAC 0236 & 4.271 & 595.633 & 6 & 432.166 & 7 & 669.936 & 7 \\
\hline CPAC 02144 & 4.241 & 662.767 & 8 & 475.930 & 8 & 747.693 & 9 \\
\hline CPAC 02167 & 4.447 & 384.050 & 2 & 344.052 & 3 & 402.232 & 2 \\
\hline CPAC 02181 & 4.045 & 893.797 & 11 & 723.007 & 10 & 971.429 & 11 \\
\hline PF 013405 & 3.146 & 2.425 .737 & 13 & 3.125 .954 & 13 & 2.107 .456 & 14 \\
\hline PF 013431 & 3.034 & 2.550 .217 & 14 & 3.818 .008 & 14 & 1.973 .949 & 13 \\
\hline PF 013453 & 3.879 & 1.057 .302 & 12 & 1.173 .249 & 12 & 1.004 .599 & 12 \\
\hline
\end{tabular}




\section{Conclusões}

1. A cultivar BRS 264 é superior em todas as condições do Cerrado do Brasil Central (adaptabilidade ampla).

2. A linhagem CPAC 02167 tem potencial para ser lançada como nova cultivar de trigo irrigado, em todas as condições do Cerrado do Brasil Central (adaptabilidade ampla).

3. São recomendadas, para condições favoráveis, as cultivares BRS 207 e EMBRAPA 22, e para condições desfavoráveis, as cultivares BRS 254 e EMBRAPA 42.

\section{Referências}

ALBRECHT, J.C.; SILVA, M.S. e; ANDRADE, J.M.V. de; SCHEEREN, P.L.; SOARES SOBRINHO, J.; CANOVAS, A.; SOUSA, C.N. de; BRAZ, A.J.B.P.; RIBEIRO JUNIOR, W.Q.; TRINDADE, M. da G.; SOUSA, M.A. de; FRONZA, V.; YAMANAKA, C.H. Trigo BRS 207: cultivar com alto potencial de produtividade indicada para os Estados de Minas Gerais, Goiás e o Distrito Federal. Planaltina: Embrapa Cerrados, 2005. 22p. (Documentos, 137).

ALBRECHT, J.C.; SILVA, M.S. e; ANDRADE, J.M.V. de; SCHEEREN, P.L.; TRINDADE, M. da G.; SOARES SOBRINHO, J.; SOUSA, C.N.A. de; BRAZ, A.J.B.P.; RIBEIRO JUNIOR, W.Q.; SOUSA, M.A. de; FRONZA, V.; YAMANAKA, C.H. Trigo BRS 264: cultivar precoce com alto rendimento de grãos indicada para o Cerrado do Brasil Central. Planaltina: Embrapa Cerrados, 2006a. 18p.

ALBRECHT, J.C.; SILVA, M.S. e; ANDRADE, J.M.V. de; SOARES SOBRINHO, J.; SOUSA, C.N. de; SOUSA, M.A. de; BRAZ, A.J.B.P.; RIBEIRO JUNIOR, W.Q.; TRINDADE, M. da G.; YAMANAKA, C.H. EMBRAPA 22: cultivar de trigo irrigado para Minas Gerais, Goiás, Mato Grosso, Bahia e Distrito Federal. Planaltina: Embrapa Cerrados, 2006b. 14p. (Documentos, 167).

ALBRECHT, J.C.; SILVA, M.S. e; ANDRADE, J.M.V. de; SOUSA, C.N. de; BRAZ, A.J.B.P.; VANDERLEI, J.C. Trigo EMBRAPA 42: cultivar para os triticultores de Goiás e Distrito Federal. Planaltina: Embrapa Cerrados, 2004. 17p.

ALLARD, R.W. Principles of plant breeding. $2^{\text {nd }}$ ed. New York: John Wiley \& Sons, 1999. 254p.

AMORIM, E.P.; CAMARGO, C.E.O.; FERREIRA FILHO, A.W.P.; PETTINELLI JUNIOR, A.; GALLO, P.B.; AZEVEDO FILHO, J.A. Adaptabilidade e estabilidade de linhagens de trigo no Estado de São Paulo. Bragantia, v.65, p.575-582, 2006.

CAEIRÃO, E.; SILVA, M.S. e; SCHEEREN, P.L.; DEL DUCA, L. de J.A.; NASCIMENTO JÚNIOR, A. do; PIRES, J.L. Análise da adaptabilidade e da estabilidade de genótipos de trigo como ferramenta auxiliar na recomendação de novas cultivares. Ciência Rural, v.36, p.1112-1117, 2006.

CARBONELL, S.A.M.; AZEVEDO FILHO, J.A.; DIAS, L.A.S.; GONÇALVES, C.; ANTONIO, C.B. Adaptabilidade e estabilidade de produção de cultivares e linhagens de feijoeiro no Estado de São Paulo. Bragantia, v.60, p.69-77, 2001.

CARGNIN, A.; SOUZA, M.A. de; CARNEIRO, P.C.S.; SOFIATTI, V. Interação entre genótipos e ambientes e implicações em ganhos com seleção em trigo. Pesquisa Agropecuária Brasileira, v.41, p.987-993, 2006a.

CARGNIN, A.; SOUZA, M.A.; DIAS, D.C.F.S.; MACHADO, J.C.; MACHADO, C.G.; SOFIATTI, V. Tolerância ao estresse de calor em genótipos de trigo na fase de germinação. Bragantia, v.65, p.245-251, 2006b.

CARNEIRO, P.C.S. Novas metodologias de análise da adaptabilidade e estabilidade de comportamento. 1998. 168p. Tese (Doutorado) - Universidade Federal de Viçosa, Viçosa.

CARVALHO, C.G.P. de; ARIAS, C.A.A.; TOLEDO, J.F.F. de; ALMEIDA, L.A. de; KIIHL, R.A. de S.; OLIVEIRA, M.F. de. Interação genótipo $\mathrm{x}$ ambiente no desempenho produtivo da soja no Paraná. Pesquisa Agropecuária Brasileira, v.37, p.989-1000, 2002.

CARVALHO, H.W.L. de; CARDOSO, M.J.; LEAL, M. de L. da S.; SANTOS, M.X. dos; TABOSA, J.N. Adaptabilidade e estabilidade de cultivares de milho no Nordeste brasileiro. Pesquisa Agropecuária Brasileira, v.35, p.1115-1123, 2000.

CRUZ, C.D. Programa Genes: versão Windows : biometria. Viçosa: UFV, 2006. 381p.

CRUZ, C.D.; CARNEIRO, P.C.S. Modelos biométricos aplicados ao melhoramento de plantas. 3.ed. Viçosa: UFV, 2003. 585p.

CRUZ, C.D.; REGAZZI, A.J. Modelos biométricos aplicados ao melhoramento genético. 2.ed. Viçosa: UFV, 1997. 390p.

CRUZ, C.D.; TORRES, R.A. de; VENCOVSKY, R. An alternative approach to the stability analysis proposed by Silva and Barreto. Revista Brasileira de Genética, v.12, p.567-580, 1989.

EBERHART, S.A.; RUSSELL, W.A. Stability parameters for comparing varieties. Crop Science, v.6, p.36-40, 1966.

FELICIO, J.C.; CAMARGO, C.E. de O.; FERREIRA-FILHO, A.W.P.; GALLO, P.B. Avaliação de genótipos de triticale e trigo em ambientes favoráveis e desfavoráveis no Estado de São Paulo. Bragantia, v.60, p.83-91, 2001a.

FELICIO, J.C.; CAMARGO, C.E. de O.; GERMANI, R.; GALLO, P.B.; PEREIRA, J.C.V.N.A.; BORTOLETTO, N.; PETTINELLIJUNIOR, A. Influência do ambiente no rendimento e na qualidade de grãos de genótipos de trigo com irrigação por aspersão no Estado de São Paulo. Bragantia, v.60, p.111-120, 2001b.

KUMAR, N.; KULWAL, P.L.; BALYAN, H.S.; GUPTA, P.K. QTL mapping for yield and yield contributing traits in two mapping populations of bread wheat. Molecular Breeding, v.19, p.163$177,2007$.

LIN, C.S.; BINNS, M.R. A superiority measure of cultivar performance for cultivar $x$ location data. Canadian Journal of Plant Science, v.68, p.193-198, 1988.

LÚCIO, A.D.; STORCK, L.; BANZATTO, D.A. Classificação dos experimentos de competição de cultivares quanto a sua precisão. Pesquisa Agropecuária Gaúcha, v.5, p.99-103, 1999. 
OLIVEIRA, E.J. de; GODOY, I.J. de; MORAES, A.R.A. de; MARTINS, A.L.M.; PEREIRA, J.C.V.N.A.; BORTOLETTO, N.; KASAI, F.S. Adaptabilidade e estabilidade de genótipos de amendoim de porte rasteiro. Pesquisa Agropecuária Brasileira, v.41, p.12531260, 2006a.

OLIVEIRA, V.O.; CARNEIRO, P.C.S.; CARNEIRO, J.E. de S.; CRUZ, C.D. Adaptabilidade e estabilidade de linhagens de feijãocomum em Minas Gerais. Pesquisa Agropecuária Brasileira, v.41, p.257-265, 2006b.

REUNIÃO DA COMISSÃO CENTRO BRASILEIRA DE PESQUISA DE TRIGO, 13., 2004, Goiânia. Informações técnicas para a cultura de trigo na região do Brasil Central: safras 2005 e 2006. Santo Antônio de Goiás: Embrapa Arroz e Feijão; Planaltina: Embrapa Cerrados; Passo Fundo: Embrapa Trigo, 2005. 82p. (Documentos, 173).
SILVA, W.C.J. e; DUARTE, J.B. Métodos estatísticos para estudo de adaptabilidade e estabilidade fenotípica em soja. Pesquisa Agropecuária Brasileira, v.41, p.23-30, 2006.

SNAPE, J.W.; FOULKES, M.J.; SIMMONDS, J.; LEVERINGTON, M.; FISH, L.J.; WANG, Y.; CIAVARRELLA, M. Dissecting gene x environmental effects on wheat yields via QTL and physiological analysis. Euphytica, v.154, p.401-408, 2007.

SOUZA, A.A. de; FREIRE, E.C.; BRUNO, R. de L.A.; CARVALHO, L.P. de; SILVA FILHO, J.L. da; PEREIRA, W.E. Estabilidade e adaptabilidade do algodoeiro herbáceo no Cerrado do Mato Grosso e Mato Grosso do Sul. Pesquisa Agropecuária Brasileira, v.41, p.1125-1131, 2006.

SOUZA, M.A. Controle genético e resposta ao estresse de calor de cultivares de trigo. 1999. 152p. Tese (Doutorado) - Universidade Federal de Lavras, Lavras.

TAI, G.C.C. Genotypic stability analysis and its application to potato regional trials. Crop Science, v.11, p.184-190, 1971.

Recebido em 10 de agosto de 2007 e aprovado em 27 de novembro de 2007 